\title{
Representação política das mulheres em 2019 e os desafios da equidade de gênero
}

\author{
Political Representation of Women in 2019 \\ and the Challenges of Gender Equity ${ }^{1}$
}

\author{
Adriana Correa Porto ${ }^{2}$, Raquel Correa Sajonc ${ }^{3}$, \\ Marcello Riella Benites ${ }^{4}$
}

Resumo: Este artigo propõe uma reflexão sobre direitos humanos a partir dos dados sobre mulheres empossadas em cargos eletivos na política em 2019. Após um mapeamento do cenário constituído pelas eleições de 2018, propomos a criação de um Índice de Participação Feminina (IPF) capaz de aferir, em números, o tamanho da desigualdade entre os gêneros em cargos de efetivo exercício de poder. O objetivo é fazer um diagnóstico da equidade de gênero e da representatividade política na Câmara dos Deputados, no Senado Federal, na Presidência da República, no Governo do Estado e na Assembleia Legislativa, nas 27 unidades federativas do Brasil. As informações sobre o quantitativo de mulheres no Legislativo e no Executivo foram comparadas entre si, criando um ranking que pode nos dar algumas pistas sobre as diferenças observadas. Esperamos que o entendimento de como essas forças operam contribua para desmantelá-las, a fim de que homens e mulheres tenham os mesmos direitos e oportunidades, tal como preconiza a Declaração Universal dos Direitos Humanos.

Palavras-chave: Mulheres; Feminismo; Política; Gênero; Brasil.
Abstract: This article proposes a reflection on the issue of human rights based on the data of women whose inauguration was held in 2019. After tracking the scenario created by the elections of 2018, we propose the creation of an Index of Feminine Participation (IPF) for assessing, in numbers, the size of the inequality between the genres in positions of effective exercise of power. The objective is to make a diagnosis of gender equity and political

\footnotetext{
${ }^{1}$ Pesquisa apresentada no Seminário Internacional de Direitos Humanos e Comunicação Participativa, realizado nos dias 1 e 2 de julho de 2019.

${ }^{2}$ Mestre em Tecnologias da Comunicação e Cultura pela Universidade Estadual do Rio de Janeiro (UERJ). Desde 2012, atua como professora do curso de Comunicação Social da Faculdade Salesiana Maria Auxiliadora FSMA, na cidade de Macaé - RJ. Seus principais temas de pesquisas são tecnologias da comunicação, novas mídias, cultura de fã, estudos de gênero, feminismo, política e relações de poder

${ }^{3}$ Mestre em Administração/ Sustentabilidade pelo Centro Universitário FEI. Trabalha como analista de Responsabilidade Social na Federação das Indústrias dos Estado de São Paulo (Fiesp).

${ }^{4}$ Mestre em Cognição e Linguagem pela Universidade Estadual do Norte Fluminense Darcy Ribeiro (Uenf) e jornalista concursado da Assessoria de Comunicação da Câmara Municipal de Macaé (CMM-RJ).
} 
representation in the Chamber of Deputies, Federal Senate, Presidency, State Government and Legislative Assembly in Brazil's 27 federative units. Data about the amount of women in the Legislative and in the Executive were compared to each other, creating a ranking that can give us some clues about the observed differences. We hope that the understanding of how these forces operate contributes to dismantle them, so that men and women have the same rights and opportunities, as set forth in the Universal Declaration of Human Rights.

Keywords: Women; Feminism; Politics; Genre; Brazil.

\section{Introdução}

As conquistas dos Direitos Humanos representam passo essencial para o progresso civilizatório. Nesse sentido, o empoderamento das mulheres e a redução da desigualdade de gênero são uma etapa decisiva no desenvolvimento de qualquer nação do globo (ALVES, 2006). No Brasil, os últimos 80 anos foram marcados por avanços e retrocessos nos direitos das mulheres e na diminuição da desigualdade entre os gêneros. Essa dinâmica repercute na configuração atual da política, da economia e da cultura nacional. Ainda hoje, fatores como gênero, raça, orientação sexual e poder aquisitivo determinam a configuração da vida de um contingente de cidadãos. Trata-se de pessoas que, na prática, não têm acesso aos mesmos direitos que os demais e, com frequência, encontram obstáculos ao pleno exercício da sua liberdade e cidadania - embora um dos princípios básicos da Declaração Universal dos Direitos Humanos (1948) seja o seu carácter universal e equânime para todos. Não obstante a isso, observamos que até mesmo o país de origem determina se o indivíduo terá acesso ou não - de forma parcial ou integral - a alguns dos direitos humanos fundamentais, ou seja, aqueles associados à igualdade e à dignidade do ser humano (BRITO FILHO, 2004).

No caso do Brasil, onde os preconceitos atravessam o universo feminino e se materializam das mais diversas formas, estudar a questão de gênero com o intuito de propor ações para uma sociedade mais equânime nos parece não apenas justo e razoável, mas necessário. Desigualdade salarial, exclusão de alguns ambientes e postos profissionais, restrição de acesso à saúde, à educação e à ascensão social são apenas alguns dos inúmeros obstáculos enfrentados cotidianamente por mulheres no Brasil e no mundo (SABINO; LIMA, 2015). Acreditamos que o entendimento de como essas forças operam seja fundamental para desmantelá-las, a fim de que homens e mulheres tenham os mesmos direitos e oportunidades. 
Quando voltamos nossa atenção para o Brasil, percebemos um contexto em que as mulheres são maioria da população ${ }^{5}$ e dos eleitores ${ }^{6}$, possuem níveis educacionais mais elevados, maior expectativa de vida e estão cada vez mais presentes no mercado de trabalho. Ainda assim, a sua representatividade na política está entre as menores da América Latina e do globo, não alcançando sequer a cota de $30 \%$ de mulheres nos cargos eletivos. De acordo com a Lei Eleitoral 9.504/1997, o total de candidatos registrados por um partido ou coligação deve ser, no mínimo, de 30\% e, no máximo, de 70\% de candidatos de cada gênero.

Para termos uma ideia mais clara a esse respeito, em um ranking de 36 países latinoamericanos, caribenhos e ibéricos sobre mulheres nos parlamentos nacionais, o Brasil ocupa a $33^{\mathrm{a}}$ posição, com 10,7\% de eleitas. Está à frente somente de Belize $(9,4 \%)$ e do Haiti $(2,5 \%)$, e muito distante das primeiras posições, ocupadas respectivamente por Cuba e Bolívia, com participação feminina de 53,2\% e 53,1\%. Em toda a América Latina, Caribe e Península Ibérica, a média do número de mulheres parlamentares nas câmaras baixas ou únicas é de 30,7\%. Os dados são do Observatório de Igualdade de Gênero da América Latina e Caribe, da Organização das Nações Unidas $(\mathrm{ONU}) .{ }^{7} \mathrm{O}$ Brasil também ocupa as últimas posições no ranking mundial de mulheres na política, que inclui 172 países. Está posicionado em $154^{\circ}$ lugar, com 10,7\% de mulheres na Câmara e 14,8\% no Senado ${ }^{8}$. Quando observamos os cargos do executivo, a situação não é diferente. Nas duas últimas eleições (2014 e 2018), tivemos apenas uma mulher eleita governadora - primeiro Suely Campos (PP), em Roraima, e depois Fátima Bezerra (PT), no Rio Grande do Norte - cabendo às mulheres apenas 3,7\% desses cargos.

Para entendermos o motivo de tamanha disparidade entre homens e mulheres no exercício do poder, recorremos a uma pesquisa bibliográfica que nos guiou na proposta de coletar e analisar os dados sobre as mulheres eleitas em 2018 e empossadas em 2019. O objetivo é fazer um diagnóstico da equidade de gênero e da representatividade política na

\footnotetext{
${ }^{5}$ Segundo dados da última Pesquisa Nacional por Amostra de Domicílio, divulgada pelo IBGE em 2013, o Brasil possui 103,5 milhões de mulheres, o equivalente a 51,4\% da população. Disponível em: http://www.brasil.gov.br/cidadania-e-justica/2015/03/mulheres-sao-maioria-da-populacao-e-ocupam-maisespaco-no-mercado-de-trabalho. Acesso em: jun. 2018.

${ }^{6} \mathrm{O}$ número de eleitoras do sexo feminino é $13,49 \%$ maior que os eleitores do sexo masculino, também de acordo com o IBGE. Disponível em: http://www.brasil.gov.br/cidadania-e-justica/2015/03/mulheres-sao-maioria-dapopulacao-e-ocupam-mais-espaco-no-mercado-de-trabalho. Acesso em: jun. 2018.

${ }^{7}$ Disponível em: https:/oig.cepal.org/pt/indicadores/poder-legislativo-porcentagem-mulheres-no-orgaolegislativo-nacional-camara-baixa-ou. Acesso em: 29 abr. 2019.

${ }^{8}$ Fonte: ONU Mulheres. Disponível em: http://www.onumulheres.org.br/noticias/brasil-e-lanterna-em-rankinglatino-americano-sobre-paridade-de-genero-na-politica/. Acesso em: 20 jun. 2018.
} 
Câmara dos Deputados, no Senado Federal, na Presidência da República, no Governo do Estado e na Assembleia Legislativa, nas 27 unidades federativas do país.

Com a utilização de dados primários e secundários, coletamos informações sobre o quantitativo de mulheres no Legislativo e no Executivo em diversas esferas políticas de poder e as comparamos entre si, criando um ranking que pode nos dar algumas pistas sobre os motivos das diferenças entre elas. Neste momento, a intenção é mapear o cenário para que, a partir desses dados, seja possível aprofundar as reflexões sobre as razões que levaram a tal configuração de poder e a um cenário tão desigual para as mulheres.

Partindo do pressuposto que a participação em cargos eletivos representa também o pleno exercício da cidadania e da própria democracia (SABINO; LIMA, 2015), acreditamos que promover o equilíbrio entre homens e mulheres na ocupação desses cargos é também fortalecer pilares legais fundamentais em nossa sociedade, como a Declaração Universal dos Direitos Humanos (1948) e a Constituição Federal Brasileira (1988). Ambas defendem os mesmos direitos para os cidadãos e proíbem a discriminação por gênero; dão legitimidade a movimentos sociais ligados aos direitos humanos, como é o caso do feminismo, e fortalecem a luta por equidade de gênero no exercício do poder, entre outras demandas que permeiam tal questão.

Este artigo ainda leva em conta a perspectiva dos Estudos Culturais, que possibilitou a reorganização do pensamento científico a partir de formas populares de expressão, resistência, contestação e alternativas à cultura dominante. Fizemos uso de tal abordagem por acreditar que o estudo da cultura, integrado aos das realidades sociais nas quais existem e se manifestam, pode nos ajudar a refletir sobre a centralidade das questões de gênero e sexualidade para a compreensão da própria categoria "poder" (ESCOSTEGUY, 2010). Essa abordagem metodológica nos permite ampliar a nossa noção de poder e compreender também o âmbito pessoal como político, trazendo novo entendimento sobre o modo como a articulação sexo/gênero e antagonismos de classe estruturam a sociedade. Contudo, tratandose de dominação, não existe estado "puro"; como qualquer manifestação cultural, essa é uma prática ambígua, fragmentária, “contaminada” (ESCOSTEGUY, 2010, p. 265). Não perder tal noção de vista, é o caminho que escolhemos para tentar dar conta da complexidade das questões envolvidas. 


\section{Justificativa e abordagem teórica}

A origem da palavra poder vem do latim potere, possum. Em seu sentido etimológico, o verbo quer dizer 'ter posse sobre algo, desempenhar o papel de senhor ou chefe da casa'. Não é à toa que a historiadora Michelle Perrot (1988) destaca poder como um termo polissêmico, associado à dominação masculina e com conotação política. Da vontade de superar a opressão simbólica e material sofrida pelas mulheres surge o movimento feminista, com o projeto de subverter o ponto de vista da dominação. Desse modo, é feito um esforço para dar visibilidade à presença e à ação das mulheres, à plenitude de seus papeis e à existência de seus poderes.

Com a Declaração de Direitos Humanos, instituída pela Organização das Nações Unidas (ONU) em 19489 , a noção de direitos humanos adquire um significado especial (WOLF, 2015), dando impulso ao feminismo, que definimos como "a luta das mulheres contra a dominação, a exclusão e a discriminação do gênero feminino na sociedade" (PORTO; SAJONC, 2017, p. 6). A luta pelo direito ao voto marca o início do movimento, que é impulsionado com a publicação da obra "O segundo sexo", de Simone de Beauvoir, em 1949. No livro, a autora aponta as razões históricas e culturais que fundaram a sociedade patriarcal, relegando à mulher uma posição subalterna. É nesse contexto que a luta por direitos humanos entra na pauta feminista, uma vez que, em sua universalidade, esses direitos não incluem as mulheres, conforme esclarece Kimberlé Crenshaw (2002, p. 172):

Embora a Declaração Universal garanta a aplicação dos direitos humanos sem distinção de gênero, no passado, os direitos das mulheres e as circunstâncias específicas em que essas sofrem abusos foram formulados como sendo diferentes da visão clássica de abuso de direitos humanos e, portanto, marginais dentro de um regime que aspirava a uma aplicação universal. Tal universalismo, entretanto, fundamentava-se firmemente nas experiências dos homens. Consequentemente, apesar da garantia formal, a proteção dos direitos humanos das mulheres foi comprometida à medida que suas experiências poderiam ser definidas como diferentes das dos homens. Assim, quando mulheres eram detidas, torturadas ou lhes eram negados outros direitos civis e políticos, de forma semelhante como acontecia com os homens, tais abusos eram obviamente percebidos como violações dos direitos humanos. Porém, quando mulheres, sob custódia, eram estupradas, espancadas no âmbito doméstico ou quando alguma tradição lhes negava acesso à tomada de decisões, suas diferenças em relação aos homens

\footnotetext{
${ }^{9}$ De acordo com a historiadora Cristina Wolf (2015), a Declaração de Direitos Humanos seria resultado da comoção causada pela divulgação das atrocidades ocorridas durante a Segunda Guerra Mundial, sobretudo contra os judeus, grupos étnicos, religiosos e políticos enviados para campos de concentração.
} 
tornavam tais abusos 'periféricos' em se tratando das garantias básicas dos direitos humanos.

Nas décadas seguintes, são formuladas propostas para o movimento feminista que, posteriormente, se junta a outros movimentos sociais. Já em meados dos anos 70, o feminismo não se funda mais na mera exigência de igualdade entre homens e mulheres, mas no reconhecimento da impossibilidade social de alcançar essa igualdade dentro de um sistema patriarcal (FOUGEYROLLAS-SCHWEBEL, 2009). O patriarcado é definido pela pesquisadora Christine Delphy (2009) como uma "formação social em que homens detêm o poder”. Para ela, é quase sinônimo de dominação masculina e opressão, sujeição e subordinação das mulheres ou da condição feminina (DELPHY, 2009, p. 173). A partir daí, surgem conceitos de sexo e gênero nos quais o primeiro era geralmente associado à natureza e o segundo, à cultura. Segundo tal ponto de vista, que prevaleceu até meados da década de 1980, o sexo se referia às diferenças biológicas entre os corpos femininos e masculinos, enquanto o gênero diria respeito às diferenças psicológicas, sociais e culturais entre homens e mulheres (SAJONC, 2017).

Uma das intelectuais feministas que mais abalou essa concepção, trazendo novas perspectivas para os estudos de gênero, foi a historiadora Joan Scott (1996), que, com seu célebre artigo Gender: A Useful Category of Historical Analysis, demarcou uma leitura pósestruturalista a respeito do gênero, explorando seus potenciais analíticos de desconstrução e ressignificação. Para a autora, gênero "é um elemento constitutivo de relações sociais baseado nas diferenças percebidas entre os sexos, e é uma forma primária de significar as relações de poder" (SCOTT, 1996, p. 1067), de tal forma que quando há mudanças sociais, essas relações também se transformam. Ela não nega que existem diferenças entre os corpos sexuados, mas, para ela, o que interessa são as formas como se constroem significados culturais para essas diferenças, dando-lhes sentido e, consequentemente, posicionando-as dentro de relações hierárquicas.

A propagação desse tipo de pensamento desmantela o argumento de que as condições em que vivem homens e mulheres são produto de um destino biológico ou natural. Ao contrário, sob este ponto de vista, tais relações são construídas socialmente e se baseiam, antes de tudo, numa hierarquia entre os sexos. Trata-se de uma relação de poder e dominação, que se exprime, sobretudo, por meio da divisão sexual do trabalho, conforme pontua a socióloga francesa Danièle Kergoat: "Essa forma de divisão social do trabalho tem dois princípios organizadores: o da separação (existem trabalhos de homens e outros de mulheres) e o da hierarquização (um trabalho de homem "vale" mais do que um de mulher)" 
[KERGOAT, 2009, p. 67]. Para ela, as relações de dominação entre os gêneros se desdobram no espaço social, público e privado, impondo às mulheres certas práticas sociais que as deixariam em situação desfavorável para alcançar cargos de efetivo exercício de poder legitimados pela sociedade patriarcal como masculinos.

Para Delphy (2009), essa articulação teria início dentro da própria família, seja em relação a mães, esposas, filhas ou irmãs. As práticas sociais impostas estariam relacionadas ao trabalho doméstico e à esfera da reprodução, estabelecendo um acúmulo de funções às mulheres que exercem atividades profissionais no mercado de trabalho ou na vida pública. Neste caso, a opressão e a exploração se somam, causando impactos na esfera política. Um desses impactos seria a aparente superficialidade e desinteresse das mulheres nas discussões e participação da política local/regional, ocasionada, principalmente, por carga mental ${ }^{10}$, acúmulo de funções e escassez de tempo.

De acordo com a filósofa Helena Hirata (2009, p. 260), “o exercício de uma atividade profissional não questiona as relações de dependência [...] vivenciadas pelas mulheres, devido ao fato de que se lhes atribui o trabalho doméstico; isso implica maior rigidez na organização dos usos do tempo". Portanto, para levar adiante seus projetos profissionais incluímos aqui o ingresso na política - as mulheres, de modo geral, experimentam uma necessidade obsessiva de programação do tempo, numa tentativa de responder ao que se espera delas na vida pessoal e profissional.

\section{Métodos e instrumentos de pesquisa}

Iniciamos a coleta de dados nos sites do Tribunal Superior Eleitoral (TSE). Posteriormente, passamos aos portais da Câmara dos Deputados e do Senado Federal. Por fim, buscamos dados nos endereços eletrônicos das assembleias legislativas dos 26 estados brasileiros e do Distrito Federal. Contudo, foi necessário buscar informações em outros meios (fontes secundárias), já que algumas fontes primárias não estavam devidamente atualizadas sobretudo com relação às eleitas que, por algum motivo, não tomaram posse e tiveram a sua vaga ocupada por algum suplente. Diretórios de partidos, informações da Empresa Brasileira de Comunicação (EBC) e da ONU Mulheres foram utilizados para o cruzamento de dados. Notícias em jornais e portais da Internet também foram úteis para descobrir algumas

\footnotetext{
${ }^{10}$ Monique Haicault (1984) traz à tona a dimensão emocional que o trabalho doméstico envolve, o qual pode ocasionar transtornos mentais, dado o seu nível de exigência e dedicação. A presença constante exigida pelas atividades cotidianas, demarcadas pela repetição, é um exemplo disso. Esse custo emocional, que se reflete também na dimensão material, é chamado de 'carga mental'. Para mais informações, vide HAICAULT, Monique. La gestion ordinaire de la vie em deux. Paris, Sociologie du Travail, n. 3, 1984.
} 
mudanças na composição dos parlamentos, posteriormente também confirmadas por contato telefônico e/ou e-mail. Abaixo é possível visualizar o resultado desse trabalho, organizado em forma de ranking de participação feminina. O quadro inclui os dados de cada unidade federativa, com o número total de cadeiras em cada parlamento, homens e mulheres eleitos e o Índice de Participação Feminina (IPF):

Quadro 1 - Ranking de participação feminina nas assembleias legislativas

\begin{tabular}{|l|c|c|c|c|}
\hline \multicolumn{1}{|c|}{ Estado } & Vagas no parlamento & Homens & Mulheres & IPF \\
\hline Acre (AC) & 24 & 20 & 04 & $16,66 \%$ \\
\hline Alagoas (AL) & 27 & 22 & 05 & $18,51 \%$ \\
\hline Amapá (AP) & 24 & 16 & 08 & $33,33 \%$ \\
\hline Amazonas (AM) & 24 & 20 & 04 & $16,66 \%$ \\
\hline Bahia (BA) & 63 & 54 & 09 & $14,28 \%$ \\
\hline Ceará (CE) & 46 & 40 & 06 & $13,04 \%$ \\
\hline Distrito Federal (DF) & 24 & 21 & 03 & $12,5 \%$ \\
\hline Espírito Santo (ES) & 30 & 27 & 03 & $10 \%$ \\
\hline Goiás (GO) & 41 & 39 & 02 & $4,87 \%$ \\
\hline Maranhão (MA) & 42 & 35 & 07 & $16,66 \%$ \\
\hline Mato Grosso (MT) & 24 & 23 & 01 & $4,16 \%$ \\
\hline M. Grosso do Sul (MS) & 24 & 24 & 00 & $0 \%$ \\
\hline Minas Gerais (MG) & 77 & 67 & 10 & $12,98 \%$ \\
\hline Pará (PA) & 41 & 32 & 09 & $21,95 \%$ \\
\hline Paraíba (PB) & 36 & 31 & 05 & $13,88 \%$ \\
\hline Paraná (PR) & 54 & 50 & 04 & $7,40 \%$ \\
\hline Pernambuco (PE) & 49 & 39 & 10 & $20,40 \%$ \\
\hline Piauí (PI) & 30 & 26 & 04 & $13,33 \%$ \\
\hline Rio de Janeiro (RJ) & 67 & 58 & 12 & $17,14 \%$ \\
\hline R. Grande Norte (RN) & 24 & 21 & 03 & $12,5 \%$ \\
\hline Rio Grande do Sul (RS) & 55 & 46 & 09 & $16,36 \%$ \\
\hline Rondônia (RO) & 24 & 22 & 02 & $8,33 \%$ \\
\hline Roraima (RR) & 24 & 18 & 07 & $29,16 \%$ \\
\hline Santa Catarina (SC) & 40 & 35 & 05 & $12,5 \%$ \\
\hline São Paulo (SP) & 94 & 76 & 18 & $19,14 \%$ \\
\hline Sergipe (SE) & 24 & 18 & 06 & $25 \%$ \\
\hline Tocantins (TO) & 24 & 05 & $20,83 \%$ \\
\hline TOTAL & 1.056 & 161 & $15,24 \%$ \\
\hline
\end{tabular}

Observando a tabela, verificamos que as mulheres representam 15\% dos deputados estaduais em exercício na atualidade. Em todo país, elegemos 161 deputadas estaduais, com um aumento de cerca de $40 \%$ em relação ao número de 2014 - ainda assim, é um índice demasiadamente baixo e desigual para os padrões internacionais. Alguns casos chamam a atenção, como o do Mato Grosso do Sul. Dos 24 deputados estaduais eleitos, nenhum é do sexo feminino. Além disso, apenas dois estados (Roraima e Amapá) se aproximam dos 30\% 
de representatividade feminina, conforme recomenda a legislação brasileira. Mais da metade das 27 unidades da federação não chega a 15\% de IPF.

Já quando o assunto são os cargos para o governo do estado, a situação é ainda mais crítica. Na última eleição, tivemos apenas uma mulher eleita governadora em todo país como já foi mencionado anteriormente. Em um universo de 200 candidatos, apenas 30 eram mulheres a disputar um cargo de governador(a) de estado em 2018. Entre as 27 unidades da federação, oito não tiveram uma candidata sequer. É o caso de Alagoas, Amapá, Ceará, Mato Grosso, Mato Grosso do Sul, Pará, Rio Grande do Sul e Rondônia. Os estados com mais mulheres em disputa foram Pernambuco e Piauí, com três candidatas cada um. No entanto, a média de candidatos em todo país foi de 7,4 por unidade da federação.

Figura 1 - Ocupação por gênero em cargos de governador de estado

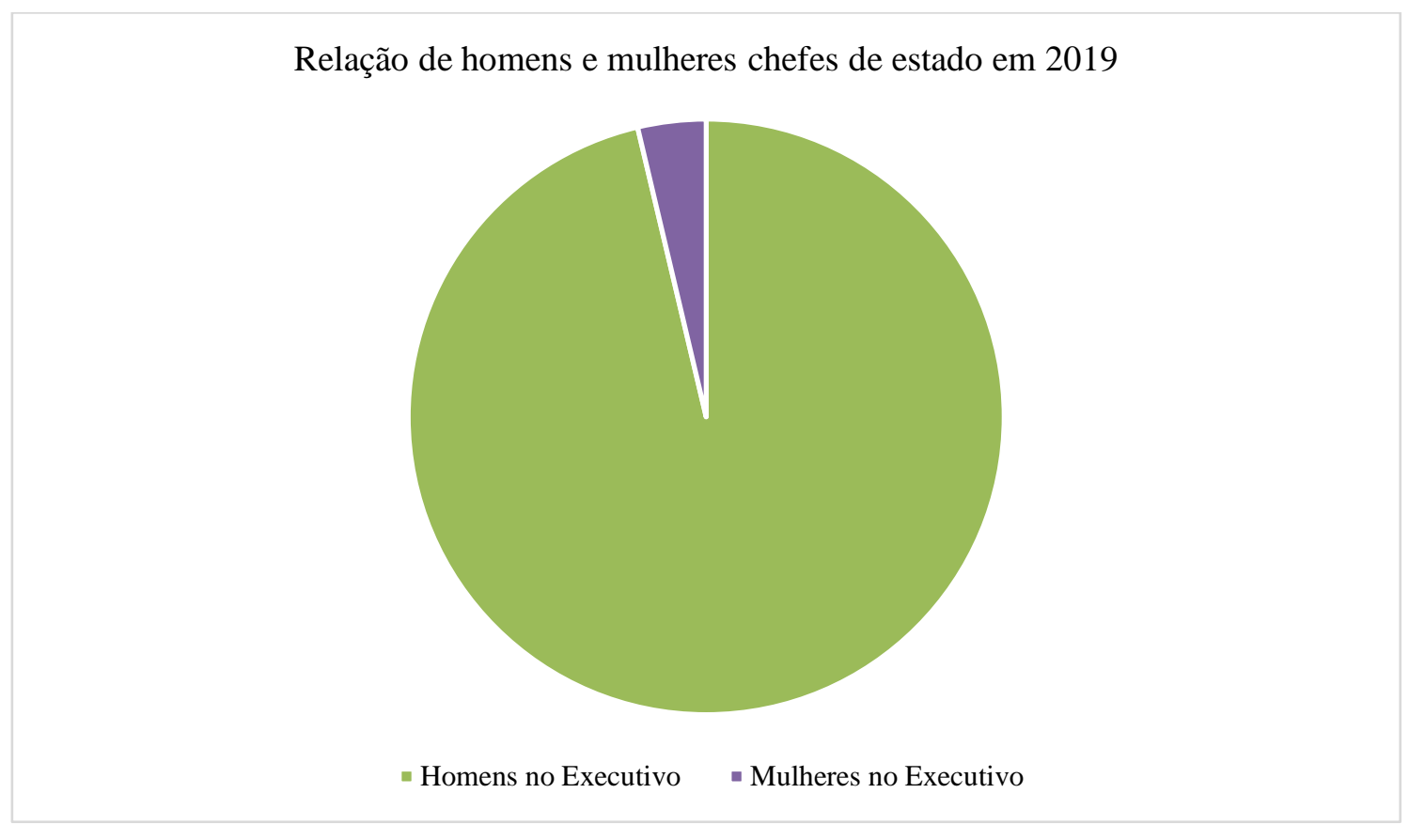

Ainda não sabemos, ao certo, os motivos que levam alguns estados a terem um IPF maior ou menor que outros, mas este levantamento é o primeiro passo para que possamos investigar e comparar tais realidades. Vale destacar, ainda, que o que acontece na esfera estadual nem sempre se repete na federal, assim como o IPF nos cargos executivos nem sempre corresponde aos índices do legislativo. Então, para entender o cenário nas diferentes esferas e regiões do país, é preciso uma análise mais apurada, que cruze esses dados e leve em conta os contextos locais - o que deve ser feito em um segundo momento desta pesquisa.

Sobre a bancada feminina no Senado, observamos que foi reduzida a partir de 2019 de 13 para 12 senadoras. Isto é, atualmente elas representam $14,8 \%$ do total de vagas. As 
outras $86,2 \%$ são ocupadas por homens. Sete foram eleitas, quatro permaneceram com o mandato e uma suplente assumiu a vaga do titular. Vale destacar que nenhuma mulher foi eleita para o Senado em 20 estados - em três deles, Acre, Bahia e Tocantins, sequer houve candidatas. De todos os 353 candidatos que disputaram uma vaga no Senado, apenas 17,5\% eram mulheres. O Mato Grosso do Sul é o único estado com duas representantes do sexo feminino. Outros 15 estados não possuem sequem uma senadora. São eles: Amapá, Amazonas, Ceará, Bahia, Goiás, Minas Gerais, Pará, Pernambuco, Piauí, Paraná, Rio de Janeiro, Rondônia, Roraima, Santa Catarina e Rio Grande do Sul. Cada uma das demais unidades da federação têm apenas uma cadeira ocupada por uma mulher.

Figura 2 - Composição por gênero no Senado Federal a partir de 2019

Proporção de homens e mulheres após a eleição de 2018

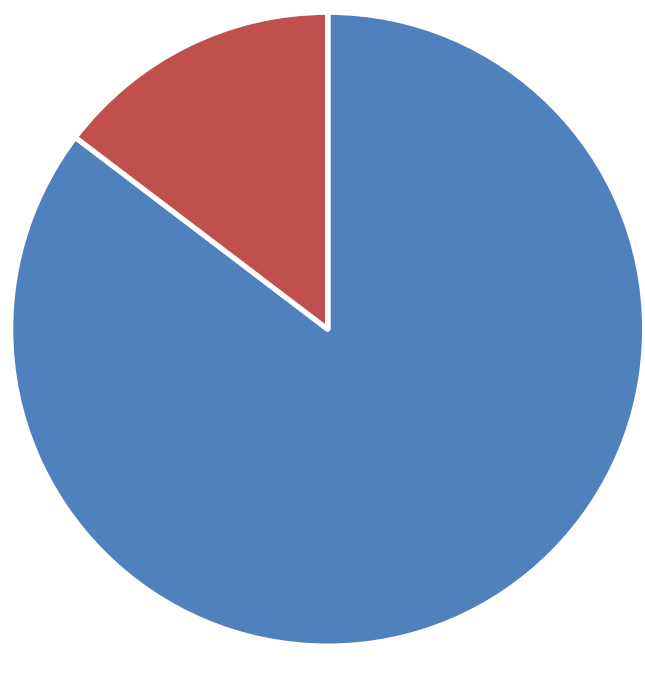

- Homens no Senado $\quad$ Mulheres no Senado

Na Câmara de Deputados, as mulheres ocupam 77 das 513 cadeiras, a maior bancada feminina da história. O IPF de 10\% na legislatura passada - 55 deputadas em 2014 - saltou para $15 \%$ em 2019. Apesar do aumento no número de deputadas federais, três estados não elegeram nenhuma mulher para o cargo: Amazonas, Maranhão e Sergipe. Proporcionalmente, o Distrito Federal foi o ente da Federação que mais elegeu deputadas: cinco mulheres em uma bancada composta por oito deputados. Depois vêm o Acre, em que quatro candidatas ocuparam metade das cadeiras, e o Piauí, com seis vagas e quatro deputadas eleitas. Em seguida estão os estados de Rondônia e Amapá; cada um que elegeu três mulheres em um total de oito vagas. Em termos absolutos, o estado com maior número de deputadas é São Paulo, com 11 mulheres em uma bancada de 70 deputados. 
Quadro 2 - Ranking de participação feminina na Câmara Federal

\begin{tabular}{|l|c|c|c|c|}
\hline \multicolumn{1}{|c|}{ Estado } & Vagas no parlamento & Homens & Mulheres & IPF \\
\hline Acre (AC) & 08 & 04 & 04 & $50 \%$ \\
\hline Alagoas (AL) & 09 & 08 & 01 & $11,11 \%$ \\
\hline Amapá (AP) & 08 & 05 & 03 & $37,5 \%$ \\
\hline Amazonas (AM) & 08 & 08 & - & - \\
\hline Bahia (BA) & 39 & 36 & 03 & $7,69 \%$ \\
\hline Ceará (CE) & 22 & 21 & 01 & $4,54 \%$ \\
\hline Distrito Federal (DF) & 08 & 03 & 05 & $62,5 \%$ \\
\hline Espírito Santo (ES) & 10 & 07 & 03 & $30 \%$ \\
\hline Goiás (GO) & 17 & 15 & 02 & $11,7 \%$ \\
\hline Maranhão (MA) & 18 & 18 & - & - \\
\hline Mato Grosso (MT) & 08 & 07 & 01 & $12,5 \%$ \\
\hline M. Grosso do Sul (MS) & 08 & 06 & 02 & $25 \%$ \\
\hline Minas Gerais (MG) & 53 & 49 & 04 & $7,54 \%$ \\
\hline Pará (PA) & 17 & 16 & 01 & $5,8 \%$ \\
\hline Paraíba (PB) & 12 & 11 & 01 & $8,3 \%$ \\
\hline Paraná (PR) & 30 & 25 & 05 & $16,66 \%$ \\
\hline Pernambuco (PE) & 25 & 24 & 01 & $4 \%$ \\
\hline Piauí (PI) & 10 & 06 & 04 & $40 \%$ \\
\hline Rio de Janeiro (RJ) & 46 & 36 & 10 & $21,73 \%$ \\
\hline R. Grande Norte (RN) & 08 & 07 & 01 & $12,5 \%$ \\
\hline Rio Grande do Sul (RS) & 31 & 28 & 03 & $9,67 \%$ \\
\hline Rondônia (RO) & 08 & 05 & 03 & $37,5 \%$ \\
\hline Roraima (RR) & 08 & 06 & 02 & $25 \%$ \\
\hline Santa Catarina (SC) & 16 & 12 & 04 & $16 \%$ \\
\hline São Paulo (SP) & 70 & 59 & 11 & $15,71 \%$ \\
\hline Sergipe (SE) & 08 & 08 & - & - \\
\hline Tocantins (TO) & 08 & 06 & 02 & $25 \%$ \\
\hline TOTAL & 513 & 77 & $15 \%$ \\
\hline
\end{tabular}

Mesmo com a melhoria na representatividade feminina, de forma geral, no legislativo, a proporção de mulheres segue abaixo do encontrado na população brasileira. No país, a cada dez pessoas, cinco são do sexo feminino. Lembramos que a recomendação da ONU é que a representação política siga a proporção da população - este é um dos parâmetros para medir o grau de desenvolvimento de uma nação.

Para se ter uma ideia mais clara sobre o atraso do Brasil com relação às demais nações do globo, recorremos também à União Interparlamentar Internacional (UIP) ${ }^{11}$. Segundo informações divulgadas pela entidade, o Brasil ocupa a $134^{\mathrm{a}}$ posição no ranking de representatividade feminina na política - muito atrás de países como Paquistão $\left(101^{\mathrm{a}}\right)$, Venezuela $\left(89^{\mathrm{a}}\right)$, Somália $\left(75^{\mathrm{a}}\right)$ e Afeganistão $\left(60^{\mathrm{a}}\right)$.

${ }^{11}$ Ranking disponível em http://archive.ipu.org/wmn-e/classif.htm. Acesso em: 25 abr. 2019. 
De modo geral, observamos uma sensível melhora no IPF - em especial na Câmara dos Deputados e nas assembleias legislativas estaduais (ambas estão em torno de 15\%). Porém, vivemos um retrocesso no Senado Federal, com a redução de um IPF que já era demasiadamente baixo (caiu de $16 \%$ para 14,8\%). Com relação aos cargos do Executivo (governo de estado), os índices se mantêm em inexpressivos $4 \%$. Confira o comparativo:

\section{Figura 3 - Evolução da participação das mulheres nas últimas eleições}

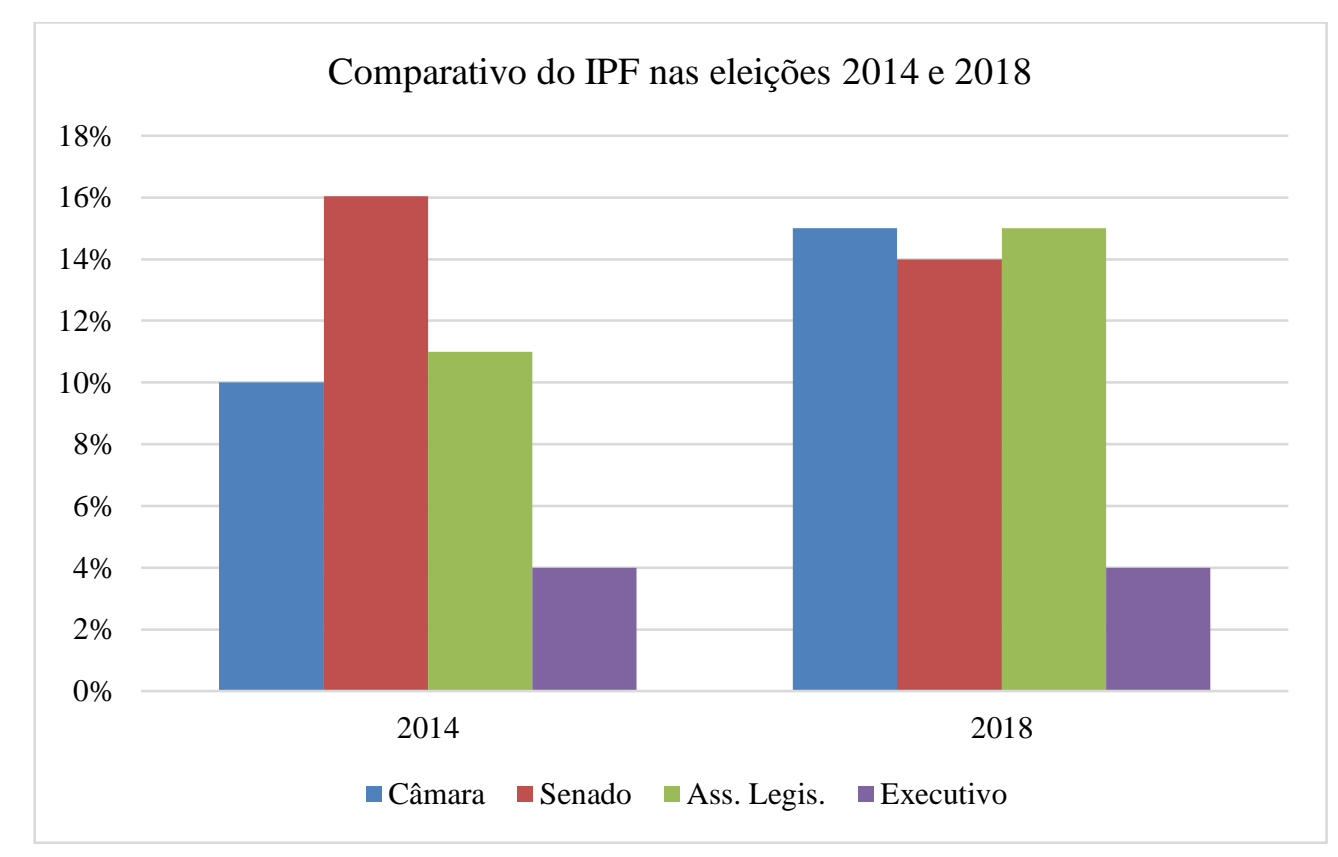

A pesquisa não considerou prefeituras e câmaras municipais, pois se baseou apenas no pleito de 2018, que elegeu deputados estaduais, federais, senadores, governadores de estado e presidente da República.

\section{Considerações finais}

Os dados coletados nesta pesquisa nos mostram que, embora haja alguns avanços, o desafio de superar a desigualdade e a discriminação de gênero no Brasil ainda é imenso. Desde 1997, a lei eleitoral brasileira exige que os partidos e as coligações respeitem a cota mínima de $30 \%$ de mulheres na lista de candidatos para a Câmara dos Deputados, a Câmara 
Legislativa, as assembleias legislativas e as câmaras municipais. Mesmo assim, no último pleito, diversos partidos e coligações foram notificados por descumprir a Lei 9.504/97 ${ }^{12}$.

Contudo, as mulheres também tiveram uma importante conquista. Em maio de 2018, o TSE decidiu que os partidos devem repassar 30\% dos recursos do Fundo Especial de Financiamento de Campanha (FEFC) para candidaturas femininas. A mudança aconteceu a partir da militância feminina e das inúmeras denúncias de candidaturas "laranja", ou seja, apenas para preencher a cota de mulheres, que não recebiam espaço ou investimentos do partido e não tinham chances reais de vencer uma eleição. Sabemos que a falta de políticas afirmativas e leis eficientes, que intentem de fato a equidade de gênero, mantêm as estruturas do patriarcado no Brasil.

Não podemos deixar de destacar que os casos de mulheres "laranja" na política podem pesar ainda mais sobre essa realidade, contribuindo para agravar um cenário que já é bastante cruel e desigual para as mulheres. Tal fato precisa ser mais aprofundado, pois pode mascarar o IPF em algumas situações, como no caso do Mato Grosso do Sul, que elegeu duas senadoras (maior IPF entre os entes da federação), mas não conseguiu eleger uma mulher nas 24 vagas da assembleia legislativa do estado. Reforço a necessidade de aprofundar os estudos sobre as realidades locais para entender quais são os elos que mantêm e reforçam a desigualdade de gênero em nosso país. De antemão, o que podemos destacar são casos que chamam a atenção pelo elevado nível de desigualdade, como o do Amazonas (o pior IPF da federação) que não possui mulheres no Senado, nem na Câmara Federal, tampouco no governo do estado. A representação feminina se limita a quatro deputadas estaduais das 24 vagas na assembleia legislativa do Estado.

Além do Amazonas, destacamos outros dois estados que não possuem representação feminina na Câmara dos Deputados: Sergipe e Maranhão. Outro fator preocupante é que mais da metade dos entes da federação (15 de um total de 27) não tenham representação feminina no Senado. Por fim, constatamos que somente um estado - o Amapá - alcança o mínimo de $30 \%$ de IPF na assembleia legislativa e apenas três na Câmara Federal - Rondônia, Distrito Federal e Amapá. O Amapá possui um dos melhores IPFs do país; é o único estado que alcançou 30\% de representação feminina na Câmara Federal e na Assembleia Legislativa, mas não possui mulheres no Senado, nem no Executivo. A militância feminista e a conscientização ampla para combater a desigualdade entre os gêneros me parecem ser o caminho natural para

\footnotetext{
12 Saiba mais em https://g1.globo.com/politica/eleicoes/2018/eleicao-em-numeros/noticia/2018/08/24/mesmocom-lei-proporcao-de-mulheres-nao-aumenta-nas-eleicoes-e-justica-precisa-notificar-coligacoes-para-quecumpram-cota.ghtml. Acesso em: 28 out. 2018.
} 
mudar essa realidade. No entanto, para trilhar tal caminho com êxito, é necessário haver políticas de comunicação mais participativas, que possibilitem o protagonismo feminino e mostrem tal realidade ao grande público. Além disso, é preciso investigar de forma mais ampla os fatores que obstruem o acesso das mulheres às instâncias de poder na política.

Uma vez que o conhecimento e a informação são fundamentais na formação da opinião e na tomada de atitudes políticas (ALDÉ, 2004), não seria surpresa que mulheres que detêm menor tempo para discutir e participar da vida pública demonstrassem menor interesse em participar da política do que os homens, que não foram historicamente alijados desse processo. Contudo, para fazer tal afirmação, seria necessário pesquisar amplamente o tema, tendo em vista que este comportamento pode não ser exatamente uma escolha das mulheres, mas resultado de uma dinâmica com fortes traços patriarcais, que dificulta a participação feminina de múltiplas maneiras ${ }^{13}$.

Até o momento, o que podemos afirmar é que, embora representem 7 milhões a mais de votos, as mulheres ainda estão longe de ter representação proporcional nos parlamentos e em cargos no Executivo, nas esferas estaduais e federais. Nas eleições de 2014, só 11\% dos cargos em disputa em todo o país ficaram com candidatas. Em 2019, esse percentual alcançou $16 \%^{14}$, todavia ele está muito longe dos $52 \%$ que correspondem à população brasileira. Essa desproporcionalidade também não pode ser atribuída apenas à dependência econômica mantida por parte dessas mulheres com relação aos homens - pai, cônjuge, irmão, filho ou outro. Segundo o IBGE, elas já são responsáveis pelo sustento de 37,3\% das famílias brasileiras e vem crescendo a sua participação no mercado de trabalho. Então, o mais provável é que estejamos diante de uma conjuntura de fatores que levem a esse quadro, em que a cultura e a história de dominação masculina e subjugação feminina tenham um papel bastante relevante.

\section{Referências bibliográficas}

ALVES, José Eustáquio Diniz. Desafios da equidade de gênero no século XXI. Revista Estudos Feministas, v. 24, n. 2, mai.-ago., 2016.

\footnotetext{
${ }^{13}$ O IBGE divulgou no dia 26 de abril de 2019 o resultado de uma pesquisa que revela que as mulheres brasileiras trabalham quase o dobro de horas que os homens nos afazeres domésticos e cuidados de parentes. Disponível em: https://economia.estadao.com.br/noticias/geral,ibge-mulheres-trabalham-quase-o-dobro-dehoras-que-homens-nos-cuidados-da-casa-e-parentes,70002805268?utm_source=facebook:newsfeed. Acesso em: 26 abr. 2019.

${ }^{14}$ Disponível em: http://www.tse.jus.br/imprensa/noticias-tse/2019/Marco/numero-de-mulheres-eleitas-em2018-cresce-52-6-em-relacao-a-2014. Acesso em: 26 abr. 2019.
} 
ALDÉ, Alessandra. A construção da política: democracia, cidadania e meios de comunicação de massa. Rio de Janeiro: Editora FGV, 2004.

BEAVOUIR, Simone. O segundo sexo: fatos e mitos. São Paulo: Difusão Europeia do Livro, 4. ed., 1970.

BRITO FILHO, José Cláudio Monteiro de. Direitos Humanos, cidadania, trabalho. Belém, 2004.

CRENSHAW, Kimberlé. Documento para o encontro de especialistas em aspectos da discriminação racial relativos ao gênero. Revista Estudos Feministas, v. 10, n. 1, p. 171-188, 2002.

DELPHY, Christine. Patriarcado (teorias do). In: HIRATA, Helena, et al. (Org.). Dicionário Crítico do Feminismo. São Paulo: Editora UNESP, 2009. p. 173-178.

EBC, Agência Brasil. Disponível em: http://agenciabrasil.ebc.com.br/politica/noticia/201810/camara-dos-deputados-tera-15\%25-de-mulheres. Acesso em: 20 out. 2018.

ESCOSTEGUY, Ana Carolina. Os estudos culturais. In: HOHLFELDT, Antonio; MARTINO, Luiz C.; FRANÇA, Vera Veiga (Org.). Teorias da Comunicação: Conceitos, escolas e tendências. Petrópolis: Editora Vozes, 2001.

FOUGEYROLLAS-SCHWEBEL, Dominique. Trabalho doméstico. In: HIRATA, Helena, et al. (Org.). Dicionário Crítico do Feminismo. São Paulo: Editora UNESP, 2009. p. 256-262.

GROSSI, Mírian Pillar; MIGUEL, Sônia Malheiros. Transformando a diferença: as mulheres na política. Revista Estudos Feministas, v. 9, n. 1, 2001. Disponível em: http://www.scielo.br/scielo.php?script=sci_arttext\&pid=S0104-026X2001000100010. Acesso em: jun. 2018.

HAICAULT, Monique. La gestion ordinaire de la vie em deux. Paris, Sociologie du Travail, n. 3, 1984.

HIRATA, Helena; ZARIFIAN, Philippe. Trabalho (o conceito de). In: HIRATA, Helena, et al. (Org.). Dicionário Crítico do Feminismo. São Paulo: Editora UNESP, 2009. p. 251-256.

KERGOAT, Danièle. Divisão sexual do trabalho e relações sociais de sexo. In: HIRATA, Helena, et al. (Org.). Dicionário Crítico do Feminismo. São Paulo: Editora UNESP, 2009. p. 67-79.

MONTEIRO, Ester. Lugar de mulher também é na política. In: Senado Notícias. Publicado em: 8 mar. 2016. Disponível em: https://www12.senado.leg.br/noticias/materias/2016/03/08/lugar-demulher-tambem-e-na-politica. Acesso em: 18 jun. 2018.

ONU Mulheres. Mujeres em la política: 2017. Disponível em: http://www.onumulheres. org.br/noticias/brasil-e-lanterna-em-ranking-latino-americano-sobre-paridade-de-genero-napolitica/. Acesso em: 20 jun. 2018.

PERROT, Michelle. As mulheres, o poder, a história. In: Os excluídos da história: operários, mulheres e prisioneiros. Rio de Janeiro: Paz e terra, 1988.

PORTO, A. C. S.; SAJONC, Raquel. Representação da mulher em Game of Thrones e a percepção das questões de gênero. In: X Simpósio Nacional da Abciber. São Paulo: USP, 14-16 dez. 2017.

SABINO, Maria Jordana Costa; LIMA, Patrícia Verônica Pinheiro Sales. Igualdade de gênero no exercício do poder. Revista Estudos Feministas, v. 23, n. 3, p. 713-734, 2015. Disponível em: http://dx.doi.org/10.1590/0104-026X2015v23n3p713. Acesso em: 11 jun. 2018. 
SAJONC, Raquel C. Redes e equidade de gênero: um estudo qualitativo exploratório de duas experiências capitaneadas por mulheres executivas. Dissertação (Mestrado em Administração). FEI: 131 p., 2017.

SCOTT, Joan W. Gender a useful category of historical analysis. In: WEED, Elizabeth (Ed.). Coming to Terms: Feminism, Theory, Politics. New York: Routledge, 1989.

WELLE, Deutsche. O amargo sabor de ser uma candidata-laranja. In: Revista Carta Capital. Disponível em: https://www.cartacapital.com.br/sociedade/o-amargo-sabor-de-ser-uma-candidatalaranja. Acesso em: 20 jun. 2016.

WOLF, Cristina Scheibe. Pedaços de alma: emoções e gênero nos discursos da resistência. In: Revista Estudos Feministas. Florianópolis: UFSC, set-dez 2015. 